\title{
REFLEXIONES SOBRE LA APLICACIÓN DE CIRCUNSTANCIAS MODIFICATIVAS DE LA RESPONSABILIDAD CRIMINAL AL HILO DE LA SAP MADRID NÚM. 519/2015, DE 17 DE JULIO, Y LA STS NÚM. 357/2016, DE 24 DE ABRIL ${ }^{1}$
}

\author{
Dra. Carmen Pérez-Sauquillo Muñoz \\ Doctora en Derecho, Universidad de Alcalá \\ Investigadora de Derecho penal.
}

Resumen: El presente artículo tiene el propósito de analizar la calificación jurídica de los hechos probados en la SAP de Madrid núm. 519/2015, de 17 de julio, y en la STS núm. 357/2016, de 24 de abril, que resuelve el recurso de casación interpuesto contra la primera. Desde un punto de vista de Derecho penal sustantivo, tales hechos plantean varios problemas relacionados tanto con la parte general como con la parte especial del Derecho penal: así, el caso ofrece una buena oportunidad para reflexionar sobre cuestiones como la tentativa de delito, los concursos y, sobre todo, la correcta comprensión y aplicación de las circunstancias modificativas de la responsabilidad criminal.

Palabras clave: Tentativa; concurso de delitos; concurso de leyes o normas; circunstancias modificativas de la responsabilidad criminal genéricas; elementos típicos agravatorios o cualificantes y atenuatorios o privilegiantes; eximentes incompletas o atenuantes privilegiadas; atenuantes ordinarias muy cualificadas y simples; atenuante analógica; atenuante

1 El presente trabajo ha sido financiado gracias al proyecto de investigación DER201458546-R sobre «Responsabilidad penal de personas físicas y jurídicas en el ámbito empresarial, económico, laboral y de los mercados (II)», dirigido por el Prof. Dr. Dr. h.c. mult. Diego-Manuel LuZón PeÑa.

Abreviaturas empleadas: CE: Constitución española; CP: Código Penal; FJ: Fundamento jurídico; DP: Derecho Penal; LECrim: Ley de Enjuiciamiento Criminal; PG: Parte General; SAP: Sentencia de la Audiencia Provincial; STS: Sentencia del Tribunal Supremo. 
de grave adicción a las drogas o al alcohol, atenuante de estados pasionales, atenuante de confesión, agravante de alevosía, circunstancia mixta de parentesco.

\section{Hechos probados}

Según se informa en la SAP de Madrid núm. 519/2015, de 17 de julio, los hechos probados del suceso objeto de análisis son, a grandes rasgos, los siguientes:

Con fecha de 19 de octubre de 2013, Jesús Ángel y su compañera Tatiana - mayores de edad y sin antecedentes penales - iniciaron una discusión en un bar cercano a su domicilio. Ambos convivían desde hacía al menos un año: cuatro meses en el referido inmueble y antes compartiendo una habitación en otra casa. Tatiana arrastraba problemas con el alcohol desde hacía años y había bebido considerablemente durante ese día, ingiriendo una cantidad notable de cerveza que le había causado un estado de embriaguez capaz de afectar a sus facultades intelectivas y volitivas, aunque sin llegar a anularlas. En un momento dado de la discusión, motivada por la petición de las llaves de la casa, Jesús Ángel resultó agredido por un varón cuya identidad y circunstancias no han sido objeto de prueba ni esclarecimiento, con un resultado de lesiones en la cara que tampoco han sido juzgadas.

Tras dicho altercado Jesús Ángel regresó al domicilio, seguido al poco tiempo por Tatiana. Al verla de nuevo, este le recriminó que le hubieran pegado por su culpa y, en un estado de frustración derivado de la agresión, se sentó en la cama de su dormitorio, apoyando la cabeza entre sus manos y sin atender a la puerta. En ese momento Tatiana cogió dos cuchillos de cocina, uno de ellos con una hoja de $14,5 \mathrm{~cm}$., y, entrando en el dormitorio y aproximándose a Jesús Ángel por detrás con intención de acabar con su vida, le clavó el cuchillo de mayores dimensiones en la espalda - concretamente, en el hemitórax derecho, a la altura de la vértebra dorsal cuarta-, saliendo a continuación de la habitación y dejándole el cuchillo clavado. Con motivo de esta cuchillada le causó una herida incisa de $1,5 \mathrm{~cm}$. de ancho y $5 \mathrm{~cm}$. de profundidad, que provocó fractura del arco posterior de la tercera costilla derecha y llegó al alcanzar el pulmón derecho, con derrame pleural, neumotórax y consecuente insuficiencia respiratoria.

Jesús Ángel se arrancó el arma de la espalda, la tiró al suelo y llamó inmediatamente por teléfono al 112 para dar cuenta de lo sucedido. Al domicilio acudieron rápidamente efectivos del servicio de urgencias y cuatro policías locales, quienes, además de ver a Jesús Ángel en el quicio de la puerta, hallaron a Tatiana sentada en la cama de su dormitorio, con el torso desnudo y uno de los cuchillos de cocina sobre la mesilla de noche. Al ver a los agentes, Tatiana les refirió espontáneamente que había 
apuñalado a su pareja con el otro cuchillo, «el grande», y también —en alusión a Jesús Ángel- que tenía que matarle, añadiendo que estaba harta de malos tratos y que Jesús Ángel le había dado un "guantazo». A pesar de que Tatiana había sido objeto de malos tratos por una pareja anterior, la causa abierta contra Jesús Ángel por un delito de malos tratos fue sobreseída por parte del Juzgado de Violencia contra la Mujer competente y ese sobreseimiento fue posteriormente confirmado por la Audiencia Provincial.

Por su parte, los efectivos del servicio de urgencias lograron estabilizar a Jesús Ángel, consiguiendo con su pronta intervención salvarle la vida y trasladarlo al Hospital Universitario, donde fue intervenido quirúrgicamente y permaneció ingresado en la unidad de cuidados críticos. Según el informe médico forense, Jesús Ángel recuperó la salud en un período de 45 días impeditivos, de los cuales 7 fueron de hospitalización. Le quedaron como secuelas dos cicatrices que implican un perjuicio estético ligero.

\section{Calificación jurídica de los hechos}

Desde un punto de vista de Derecho penal sustantivo, que es el que interesa a los efectos del presente comentario, los hechos relatados plantean varios problemas relacionados tanto con la parte general como con la parte especial del Derecho penal: así, el caso ofrece una buena oportunidad para reflexionar sobre cuestiones como la tentativa de delito, los concursos y, sobre todo, la correcta comprensión y aplicación de las circunstancias modificativas de la responsabilidad criminal.

El asunto fue resuelto en única instancia por la sección $23 .^{a}$ de la Audiencia Provincial de Madrid en su ya referida SAP núm. 519/2015, de 17 de julio. En ella, el tribunal condenó a Tatiana como autora de un asesinato en grado de tentativa (arts. 139 e.r.c. arts. 16 y 62 CP) con la concurrencia de la circunstancia atenuante simple de embriaguez (art. 21.2. ${ }^{\mathrm{a}} \mathrm{CP}$ ), de la atenuante analógica de confesión (art. 21.7. ${ }^{\mathrm{a}}$ e.r.c. art. 21.4. ${ }^{a} \mathrm{CP}$ ) y la circunstancia agravante de parentesco (art. $23 \mathrm{CP}$ ). La pena impuesta fue de siete años y seis meses de prisión, con inhabilitación especial para el ejercicio del derecho de sufragio pasivo durante el tiempo de la condena. Además, de conformidad con lo previsto en los artículos 57.2 y $48 \mathrm{CP}$, impuso a Tatiana la prohibición de aproximarse a Jesús Ángel a su domicilio, a su lugar de trabajo o a cualquier otro que frecuentase, en una distancia de $300 \mathrm{~m}$. y durante el plazo de 10 años. En concepto de responsabilidad civil, el tribunal obligó a Tatiana a indemnizar a Jesús Ángel una suma de 4.640 euros por los días de curación impeditivos y 1.370 euros por las secuelas sufridas, más los intereses legalmente previstos. 
La sentencia fue recurrida en casación por la representación procesal de la condenada Tatiana ante el Tribunal Supremo. Entre otros ${ }^{2}$, fueron alegados los siguientes motivos de infracción de ley por vulneración de un precepto penal de carácter sustantivo (art. 849.1. ${ }^{\circ}$ LECrim $\left.^{3}\right)$ :

i) la aplicación indebida del art. $139 \mathrm{CP}$ en lugar del art. $148.1 \mathrm{CP}$ o, en su defecto, del art. $138 \mathrm{CP}$;

ii) la inaplicación indebida de la eximente completa de legítima defensa (art. 20.4. ${ }^{\circ} \mathrm{CP}$ ) o, en su defecto, de la eximente incompleta o de la atenuante muy cualificada; o, subsidiariamente a lo anterior, de la atenuante simple o analógica (arts. 21.1. ${ }^{\mathrm{a}}$ y 21.7. ${ }^{\mathrm{a}} \mathrm{CP}$ );

iii) la inaplicación indebida de la eximente completa de embriaguez (art. 20.2. ${ }^{\circ} \mathrm{CP}$ ) o, en su defecto, de la eximente incompleta o de la atenuante muy cualificada (arts. 21.1. ${ }^{\mathrm{a}}, 21.2$. $^{\mathrm{a}}$ y $21.7 \mathrm{CP}$ );

iv) la inaplicación indebida de la eximente completa de trastorno mental transitorio (art. 20.1. ${ }^{\circ} \mathrm{CP}$ ) o, en su defecto, de la eximente incompleta o de la atenuante muy cualificada; o, subsidiariamente a lo anterior, de la atenuante simple o analógica (arts. 21.1. ${ }^{\mathrm{a}}$ y $21.7 .^{\mathrm{a}} \mathrm{CP}$ );

v) la inaplicación indebida de la atenuante muy cualificada de arrebato y/u obcecación o, subsidiariamente, de la atenuante simple o analógica (arts. 21.3. ${ }^{\mathrm{a}}$ y 21.7. ${ }^{\mathrm{a}} \mathrm{CP}$ );

vi) la inaplicación indebida de la eximente completa de miedo insuperable (art. 20.6. ${ }^{\circ} \mathrm{CP}$ ) o, en su defecto, de la eximente incompleta $\mathrm{o}$ atenuante muy cualificada o, subsidiariamente, a ello como atenuante simple o analógica (arts. 21.1. ${ }^{\mathrm{a}}$ y 21.7. ${ }^{\mathrm{a}} \mathrm{CP}$ ); y

vii) la aplicación indebida de la circunstancia mixta de parentesco (art. $23 \mathrm{CP}$ ).

En su STS núm. 357/2016, de 24 de abril, el Tribunal Supremo rechazó todos y cada uno de los referidos motivos, desestimando el recurso de casación. Reiterado reproche de la Sala 2. ${ }^{a}$ a la motivación de la parte recurrente es su intento de hacer pasar como defectos de calificación jurídica - los únicos a los que se refiere el art. 849.1. ${ }^{\circ}$ LECrim invo-

2 En el recurso se alegan también otros motivos como la infracción de los arts. 24.1 y $2 \mathrm{CE}$ (vulneración del derecho a la tutela judicial efectiva, deber de motivación de la sentencia y derecho a la presunción de inocencia) y el error en la apreciación de la prueba (ex art. 849.2. ${ }^{\circ}$ LECrim). Su análisis, sin embargo, excede de las pretensiones del presente comentario.

3 «Artículo 849 LECrim. Se entenderá que ha sido infringida la Ley para el efecto de que pueda interponerse el recurso de casación: $1 .^{\circ}$ Cuando, dados los hechos que se declaren probados en las resoluciones comprendidas en los dos artículos anteriores, se hubiere infringido un precepto penal de carácter sustantivo u otra norma jurídica del mismo carácter que deba ser observada en la aplicación de la Ley penal. [...]» 
cado- lo que no serían, a su juicio, sino impugnaciones del relato de hechos considerado probado por el tribunal de instancia en su - por lo demás - razonada y motivada sentencia. Y así, el Tribunal Supremo confirma la existencia de alevosía en el momento clave del suceso enjuiciado y se muestra conforme con la aplicación por el tribunal de instancia de la agravante de parentesco y de la atenuante simple de grave adicción a las bebidas alcohólicas, drogas tóxicas, estupefacientes, etc., frente a la posibilidad de aplicar una eximente completa o incompleta (o de una atenuante muy cualificada) de intoxicación por el consumo de tales sustancias. Además, considera carentes de fundamento los argumentos de la recurrente relativos a la aplicación de eximentes y/o atenuantes de legítima defensa, trastorno mental transitorio, miedo insuperable o arrebato u obcecación, basándose en la falta de conformidad de tales alegaciones con el cuadro probatorio.

En las páginas que siguen se procederá a exponer con algo más de detalle las principales cuestiones de Derecho penal sustantivo que suscita el supuesto de hecho, partiendo para ello de un enfoque propio combinado con las aportaciones más relevantes de las dos sentencias aquí comentadas.

\section{Tentativa de asesinato. La alevosía como agravante genérica o como elemento típico agravatorio}

Los hechos descritos realizados por Tatiana (en particular, la acción de clavar un cuchillo de 14,5 cm. de hoja en el hemitórax derecho de Jesús Ángel, a la altura de la vértebra dorsal cuarta) no eran solo objetivamente idóneos para lesionar gravemente, sino incluso para producir la muerte de la víctima, conforme a los informes médico-forenses. Además, según afirma la Audiencia Provincial de Madrid, esa última era precisamente la intención de Tatiana, como ella misma manifestó a los agentes de policía y se desprende también del instrumento escogido, la zona corporal y la fuerza y profundidad de la puñalada. Parece claro por lo tanto que, desde un punto de vista subjetivo, en su conducta concurría dolo directo de primer grado de matar.

Tales hechos pueden calificarse en principio como una tentativa idónea y acabada de asesinato. A esta conclusión se llega —en la línea de la sentencia de instancia- después de considerar, por un lado, que en ellos concurría uno de los elementos típicos agravatorios constitutivos del delito de asesinato (frente a un mero homicidio) y, por otro, que la autora no llegó a consumar el tipo al no producirse (por causas ajenas a su voluntad) el resultado típico deseado de muerte.

a) En efecto, tal y como se describen los hechos probados ha de entenderse que la autora actuó con alevosía. Aunque la alevosía puede funcionar como una circunstancia agravante genérica en algunos casos 
(art. 22.1. ${ }^{\mathrm{a}} \mathrm{CP}$ ), en otros opera como elemento típico agravatorio: ya sea en un tipo autónomo, independiente o sui generis (como es el caso precisamente del asesinato, art. 139.1.1. ${ }^{a} \mathrm{CP}$ ), o en un (sub)tipo agravado o cualificado (como las lesiones agravadas del art. 148.2. ${ }^{\circ} \mathrm{CP}$ ). La cuestión de si los hechos de este caso se ejecutaron con alevosía es por lo tanto importante a los efectos de determinar su calificación jurídica, pues en el concurso de leyes o normas existente entre el homicidio y el asesinato optaremos por este último (regla de la especialidad, art. 8.1. ${ }^{\mathrm{a}} \mathrm{CP}$ ).

Si acudimos a las sentencias comentadas, podemos observar sin embargo que la representación procesal de Tatiana descarta que concurriera este elemento típico; por eso resulta tan importante determinar su concepto. Así, según el art. 22.1. a , párr. 2. ${ }^{\circ} \mathrm{CP}$ :

«Hay alevosía cuando el culpable comete cualquiera de los delitos contra las personas empleando en la ejecución medios, modos o formas que tiendan directa o especialmente a asegurarla, sin el riesgo que para su persona pudiera proceder de la defensa por parte del ofendido.»

El Tribunal Supremo se ha pronunciado en muchas ocasiones sobre la alevosía y ha ido precisando su naturaleza, fundamento, requisitos y modalidades. En cuanto a la primera cuestión, en los últimos tiempos ha señalado que se trata de una circunstancia o elemento típico de carácter mixto, esto es, predominantemente objetivo (relativo al hecho) pero también en parte subjetivo (relativo al sujeto) ${ }^{4}$.

Su fundamento residiría ante todo en el incremento de la antijuridicidad del hecho, pues la alevosía haría la conducta más peligrosa, al facilitar la comisión del delito; no obstante —añade el Tribunal Supremo-, también afectaría a la culpabilidad, al considerarse el ánimo del agente como "particularmente ruin, perverso, cobarde o traicionero» ${ }^{5}$. Esta idea de que la alevosía afecta al injusto $y$ a la culpabilidad es compartida por la mayoría de la doctrina, pero no es unánime: la cuestión se enmarca en el debate acerca de si la culpabilidad actúa como mero filtro que bloquea o deja pasar (total o parcialmente) el injusto típico o si, por el contrario, puede añadir mayor reprochabilidad a la gravedad de este, lo cual depen-

${ }^{4}$ Vid., entre otras, las SSTS núm. 2047/2000, de 28 de diciembre (FJ 3. ${ }^{\circ}$ ), y núm. 86/2015, de 25 de febrero (FJ $1 .^{\circ}$ ). Nótese que a veces se identifica la naturaleza objetiva con el injusto y la subjetiva con la culpabilidad (así, por ejemplo, MUÑOz CONDE/GARCIA ARÁn, Derecho Penal, Parte general, 9. a ed., Valencia, Tirant lo Blanch, 2015, pp. 481-483 [libro electrónico]; STS núm. 86/2015, de 25 de febrero). Sin embargo, esto no tiene por qué ser necesariamente así, en la medida en que el injusto comprende para la mayoría de la doctrina una parte objetiva y una subjetiva: v. Luzón PEÑA, Lecciones de Derecho Penal, Parte general, 3. ${ }^{\mathrm{a}}$ ed., Valencia, Tirant lo Blanch, 2016, 12/20-21; Mir PuIG, Derecho Penal, Parte general, 10. ${ }^{a}$ ed., Barcelona, Reppertor, 2016, 10/1-2, advirtiendo sin embargo de las fronteras flexibles entre una y otra y de su carácter interdependiente.

5 STS núm. 86/2015, de 25 de febrero (FJ 1. ${ }^{\circ}$ ). 
de en parte del concepto que de culpabilidad se sostenga. Por eso, para algunos autores la alevosía únicamente afectaría a la antijuridicidad y, en concreto, al desvalor objetivo (aunque para un sector también en parte al subjetivo) de acción ${ }^{6}$.

Respecto de los requisitos o elementos de la alevosía, el Tribunal Supremo ha precisado cuatro: uno normativo, otro objetivo, otro subjetivo y otro teleológico ${ }^{7}$.

- Para empezar, la alevosía sólo puede aplicarse como agravante genérica en los «delitos contra las personas»: en la práctica de los tribunales, esta exigencia hace que sólo se aplique a los delitos de homicidio y lesiones. De todas formas, en este caso el debate sobre la extensión de su ámbito de aplicación no nos afecta, puesto que la alevosía ya viene expresamente recogida en el delito de asesinato como elemento típico agravatorio.

- En cuanto al elemento objetivo, se trata del «modus operandi» al que antes se ha hecho referencia: en otras palabras, es necesario que el autor utilice en la ejecución medios, modos o formas objetivamente adecuados para asegurarla mediante la evitación del riesgo de defensa de la víctima, sin que baste la mera convicción del sujeto acerca de su idoneidad. En la práctica, se suelen identificar varias modalidades de alevosía por la doctrina y el Tribunal Supremo: las llamadas «alevosía proditoria», la «súbita, inopinada o sorpresiva» y la de «desvalimiento», aunque respecto de esta última existe cierto debate sobre su concreto alcance ${ }^{8}$.

En el caso objeto de análisis, la alevosía encajaría en el primero o, en su defecto, en el segundo tipo, pues según los antecedentes de hecho se dice que la autora se aproximó por la espalda y de manera oculta para la víctima, lo cual supone una especie de acechanza o emboscada. Incluso en el supuesto de que Jesús Ángel pudiera oír cómo se aproximaba por detrás Tatiana (cuestión que se debate en las sentencias comentadas), este no podía esperarse un ataque súbito; entre otros motivos, por tratarse Tatiana de una persona de confianza y haberse terminado ya la discusión (por otro lado, no violenta) que ambos habían tenido. En palabras del Tribunal Supremo en su sentencia núm. 357/2016, de 24 de abril:

${ }^{6}$ Es el caso por ejemplo de Mir Puig, DP, PG, 10. ${ }^{a}$ ED., 2016, 26/3-4. Sobre este debate, vid. también LuZÓN PEÑA, Lecciones, PG, 3. ${ }^{a}$ ED., 2016, 26/45.

7 Vid., por ejemplo, las SSTS núm. 357/2005, de 20 abril (FJ 13..$^{\circ}$ y núm. 86/2015, de 25 de febrero (FJ $\left.1 .^{\circ}\right)$.

${ }^{8}$ Sobre el debate en torno a la llamada alevosía por desvalimiento, véase por ejemplo Muñoz Conde/Garcia ARÁN, DP, PG, 9. a ED., 2015, p. 493 [libro electrónico]; Mir Puig, DP, $P G, 10 .^{a}$ ED., 2016, 26/12. 
«... hay un momento en que [Jesús Ángel], mirando o no al suelo, oyendo o sin oír, ofrece su espalda a ésta [Tatiana], que puede acercarse a él fácilmente y acuchillarle por detrás sin que opusiese siquiera el menor intento de defensa. Por tanto, no hay duda, en ese momento [Jesús Ángel] no tenía ningún motivo para sospechar de la inminencia de una posible agresión; pues lo contrario habría sido rigurosamente incompatible con el modo de actuar que consta.

Así las cosas, es claro que lo que se desprende del cuadro probatorio en este punto es que hubo un momento en el que, debido a su actitud y a la posición en que se hallaba, [Jesús Ángel] estuvo realmente desprevenido e inerme frente a [Tatiana], que, por ello, consciente de la situación de ventaja pudo acometerle hundiéndole un cuchillo de grandes dimensiones en la espalda. Un arma que aquel no vio hasta que una parte de la hoja estaba ya dentro de su cuerpo» ${ }^{9}$.

- El elemento subjetivo que exige el Tribunal Supremo no es otra cosa que el dolo del autor proyectado también a la utilización de los medios, modos o formas empleados, todo ello de tal manera que se asegure la ejecución del delito al evitar la defensa de la víctima. A la vista de los hechos descritos, y como se desprende de la anterior cita del Tribunal Supremo, parece claro que Tatiana se valió conscientemente del referido "modus operandi» que convertía su ataque en algo totalmente inesperado para Jesús Ángel, por lo que puede afirmarse que tiene conocimiento y voluntad de realizar todos los elementos del tipo (positivo o indiciario) de asesinato.

- Por último, con la exigencia del elemento teleológico el Tribunal Supremo quiere asegurarse de que, valorados los hechos concretos, se aprecie una mayor antijuridicidad y - a su juicio-culpabilidad, lo que sucede en el caso analizado.

b) Dicho esto, y como ya se ha avanzado, se trata de una tentativa de asesinato, y no de un asesinato consumado. Hay tentativa cuando el sujeto da comienzo a la ejecución del delito por hechos exteriores, realizando todos o parte de los actos objetivamente necesarios para consumarlo, sin que tal consumación tenga finalmente lugar por causas ajenas a la voluntad del autor ${ }^{10}$. Al respecto, la Audiencia Provincial de Madrid se detiene en sentencia para recordar las clases de tentativa y las teorías existentes a la hora de determinar el grado de ejecución del delito, optando por una

9 FJ 1. . Nótese que, como resultado de los respectivos procesos de anonimización de sentencias, en la STS los nombres de los sujetos difieren de los empleados en la SAP de Madrid. De ahí que en la cita hayan sido modificados para que coincidan.

10 Muñoz Conde/Garcia ArÁn, DP, $P G, 9 .^{a}$ ed., 2015, pp. 412-423 [libro electrónico]; Mir Puig, DP, $P G, 10$. $^{\mathrm{a}}$ ed., 2016, 13/46-48. 
teoría mixta, que atiende no solo a la secuencia de actos verificada, sino también al plan del autor ${ }^{11}$.

En este caso, los actos de Tatiana estaban dirigidos (dolosamente) a consumar la muerte y eran idóneos para ello (de ahí que fuera tentativa idónea y no inidónea). Además, aunque sobre este punto puede haber más discusión, fueron realizados en su totalidad (tentativa acabada), no habiéndose producido sin embargo el resultado de muerte por causas ajenas a la autora, ya que fue la propia víctima la que se quitó el cuchillo y llamó al servicio de emergencias. De no haberse realizado esta llamada, la víctima habría fallecido, como reconocieron los agentes del servicio que le atendieron y se declara probado en los hechos.

\section{Lesiones consumadas: ¿concurso de normas o concurso de delitos con la tentativa de asesinato?}

A la vista de los hechos, se puede afirmar que las cuchilladas de Tatiana causaron unas lesiones dolosas consumadas, y en particular unas lesiones graves tipificadas en el art. $148.1 .^{\circ}$ y $2 .^{\circ}$, al haberse empleado armas concretamente peligrosas y concurrir también alevosía. La cuestión problemática reside en determinar si tales lesiones quedan necesariamente absorbidas en la tentativa de asesinato por tratarse de un concurso de leyes (regla de la absorción, art. 8.3. ${ }^{\mathrm{a}} \mathrm{CP}$ ) o si se trata por el contrario de un concurso ideal de delitos, en el que una única unidad de hecho (el acto de acuchillar por la espalda a la altura descrita) constituye dos delitos (art. 77.1 CP) ${ }^{12}$ : lesiones consumadas $y$ tentativa de asesinato.

Cabe apuntar sin embargo que, debido al principio acusatorio, en las sentencias de la Audiencia Provincial de Madrid y del Tribunal Supremo no se plantea la cuestión en estos exactos términos. El debate en ellas se centra en la calificación jurídica de los hechos, pues la representación procesal de Tatiana los califica de lesiones (o, en su defecto, de homicidio) y las acusaciones, en cambio, de tentativa de asesinato, al concurrir a su juicio (cosa que la contraparte discute) dolo de matar y alevosía. Esta última es la posición que amparan finalmente los dos tribunales, descartando las lesiones — «Los hechos enjuiciados [...] no pueden incardinarse en los delitos de lesiones [...]» ${ }^{13}-\mathrm{y}$ teniéndolas únicamente en cuenta a los efectos de determinar la responsabilidad civil.

11 SAP de Madrid núm. 519/2015, de 17 de julio (FJ 6. ${ }^{\circ}$ ).

12 Sobre los concursos de normas y de delitos, Vid. Luzón Peña (dir.), Enciclopedia Penal Básica, Granada, Comares, 2002; MuÑoz Conde/Garcia Arán, DP, PG, 9. a ed., 2015, pp. 465-478 [libro electrónico]; MIR PUIG, $D P, P G, 10 .^{\text {a }}$ ed., 2016, 27/1-84.

${ }_{13}$ SAP de Madrid núm. 519/2015, de 17 de julio (FJ 6. ${ }^{\circ}$ ). 
Con todo, si las acusaciones se limitan a acusar por un delito de asesinato en grado de tentativa es porque parten implícitamente de la posición favorable a la existencia de un concurso de leyes con las lesiones. Recuérdese a estos efectos que, en los concursos de leyes, ante unos hechos subsumibles en varios preceptos penales, hay un precepto que sin embargo desplaza al otro, pues abarca ya todo su desvalor (por tratarse de un hecho que acompaña normalmente a otro, o por ser actos posteriores impunes o copenados). Sin embargo, puede también defenderse (con alguna doctrina) que la tentativa de asesinato, incluso la acabada, no tiene por qué absorber unas lesiones como las descritas, que requieren 7 días de hospitalización y dejan como secuelas dos cicatrices. De seguir esta última postura (y dejando al margen cuestiones relacionadas con el principio acusatorio) habría de entenderse consecuentemente que nos hallamos ante un concurso ideal de delitos, cuya pena deberá determinarse conforme a las reglas del art. 77.2 CP.

\section{Circunstancias modificativas de la responsabilidad criminal que concurren en el caso}

Las circunstancias modificativas de la responsabilidad criminal, es decir, las circunstancias atenuantes y agravantes genéricas ${ }^{14}$, son un conjunto de elementos accidentales aplicables en principio a cualquier delito, o a una buena parte de ellos, y que reducen o aumentan la pena típica del delito en el que operan en cada caso, pero sin dar lugar a un nuevo tipo (ni privilegiado ni atenuado). Su fundamento es variable, pues pueden modificar el grado de injusto, de culpabilidad o de punibilidad, y están reguladas directamente en la parte general del CP (arts. 21-23 CP para las personas físicas, y 31 bis. 2 y 4, 31 ter.2, 31 quater para las personas jurídicas), con algunas excepciones (e.g., arts. 305.6, 307.5 y $308.7 \mathrm{CP}$ ). Normalmente se entiende que afectan al injusto aquellas circunstancias que incrementan o reducen la peligrosidad de la conducta o sus efectos sobre el bien jurídico, mientras que afectan a la culpabilidad las que se refieren a la accesibilidad a la norma penal y motivabilidad del sujeto por ella, así como a la naturaleza de los motivos que inspiran la conducta. Por último, algunas circunstancias afectan a la punibilidad por motivos de política criminal o de otra clase.

14 Cfr. ampliamente sobre las circunstancias atenuantes y agravantes, LUZÓN PEÑA (dir.), Enciclopedia Penal Básica, Granada, Comares, 2002; Muñoz Conde/Garcia Arán, DP, PG, 9. ${ }^{a}$ ed., 2015, pp. 479-500 [libro electrónico]; Maqueda Abreu/Laurenzo Copello, El Derecho penal en casos. Parte general: teoría y práctica, 4. ${ }^{\mathrm{a}}$ ed., Valencia, Tirant lo Blanch,

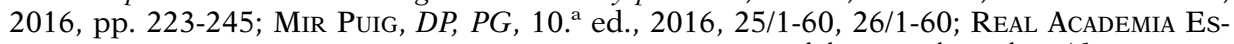
pañola/Consejo General del Poder Judicial, Diccionario del español jurídico (dir.: Muñoz Machado), Madrid, Espasa, 2016. 
Aunque en su contenido pueden coincidir, las circunstancias atenuantes y agravantes genéricas deben distinguirse en sentido estricto de las llamadas circunstancias específicas o, mejor dicho, de los elementos típicos atenuatorios - o privilegiantes- o agravatorios - o cualificantes-, que sí están incorporados al tipo penal y hacen de él un (sub)tipo derivado - privilegiado o cualificado- o un tipo autónomo, independiente o sui generis. La concurrencia de atenuantes y agravantes genéricas tiene efectos en la determinación de la pena, a cuyos efectos rigen las reglas establecidas en los arts. 65-68 CP.

Si se acude a las sentencias comentadas, llama especialmente la atención la larga enumeración de eximentes del art. $20 \mathrm{CP}$ y -ya dentro de las circunstancias modificativas de la responsabilidad criminal- de atenuantes genéricas que plantea la representación procesal de Tatiana. Interesa destacar que, por lo general, las de diferente naturaleza son alegadas de manera acumulativa, mientras que las semejantes entre sí pero de diferente intensidad son en cambio planteadas con carácter principal o subsidiario, según su mayor o menor efecto eximente o atenuatorio de la responsabilidad penal y en busca lógicamente del mayor interés de Tatiana. Además, el Ministerio Fiscal también reconoce por su parte la concurrencia de alguna circunstancia adicional.

Al hilo de esta enumeración se hace patente la diversidad de circunstancias atenuantes genéricas previstas en el CP y su diferente naturaleza, fundamento y efecto:

- Por un lado, las eximentes incompletas o atenuantes privilegiadas (art. 21.1. ${ }^{a} \mathrm{CP}$ ) responden tanto a la apreciación parcial de alguna causa de justificación por falta de uno o varios requisitos inesenciales - disminuyendo notablemente el injusto- como a situaciones de semiimputabilidad o causas de semiexculpación que reducen la culpabilidad de manera relevante. Se conectan por ello con las eximentes del art. $20 \mathrm{CP}$.

- Las atenuantes ordinarias, por otro lado, comprenden también elementos que disminuyen la imputabilidad del sujeto (arts. 21.2. y $3{ }^{\text {a }} \mathrm{CP}$ ) y circunstancias o comportamientos posteriores al delito que, por conveniencia político-criminal u otras razones ${ }^{15}$, atenúan la punibilidad del mismo, sin llegar sin embargo a excluirla (arts. 21.4. ${ }^{\mathrm{a}}$, 5. $^{\mathrm{a}}$ y $6 .^{\mathrm{a}} \mathrm{CP}$ ). A su vez, las atenuantes ordinarias pueden tener un efecto simple sobre la pena o muy cualificado, en función de la intensidad con que concurra el elemento que fundamenta la atenuación (Vid. art. 66.1.1. ${ }^{\mathrm{a}}$ y $2 .^{\mathrm{a}} \mathrm{CP}$ ).

15 En el caso de la atenuante de dilaciones indebidas, se trata más bien de una suerte de compensación parcial al delincuente por haber vulnerado el Estado su derecho constitucional del art. 24.2 CE a un proceso sin dilaciones indebidas. 
- Por último, la atenuante analógica permite reducir la pena cuando concurra una circunstancia de "análoga significación» a las atenuantes genéricas legalmente previstas, abriendo una vía expresa para la analogía in bonam partem.

Dejaremos de lado algunas de las eximentes completas e incompletas alegadas por la representación procesal de Tatiana, como la de legítima defensa o miedo insuperable, pues ninguna de ellas se corresponde - siquiera en sus requisitos esenciales- con los hechos probados, como bien reconocen la Audiencia Provincial de Madrid y el Tribunal Supremo. Así, ni Tatiana estaba siendo objeto de ninguna agresión actual por parte de Jesús Manuel ni tampoco actuó presa del miedo ${ }^{16}$.

Sí interesa detenerse en cambio en otras de las atenuantes que resultan más problemáticas en este caso: de una parte, su adicción a las bebidas alcohólicas y el haber consumido estas de modo capaz de afectar a sus facultades intelectivas y volitivas; de otra, el hecho de haber confesado a los agentes de policía su autoría del hecho; y, por último, su relación sentimental con la víctima. Al tratarse de un caso de autoría unipersonal no será necesario analizar la comunicabilidad o incomunicabilidad de las circunstancias (art. 65.1 y $2 \mathrm{CP}$ ), que sin embargo es necesario tener presente en otros casos en los que intervengan varias personas.

a) La adicción al consumo de bebidas alcohólicas y alteración de las facultades volitivas e intelectivas: ¿eximente incompleta, atenuante ordinaria $o$ atenuante analógica?

En el relato de hechos probados se nos dice que Tatiana arrastraba problemas con el alcohol desde hacía años y había bebido considerablemente durante ese día, ingiriendo una cantidad notable de cerveza que le había causado un estado de embriaguez capaz de afectar a sus facultades

16 Aclaratoria respecto de la primera cuestión resulta la siguiente reflexión de la SAP de Madrid núm. 519/2015, de 17 de julio (FJ 8. ${ }^{\circ}$ ): «Aun partiendo de que cuando Jesús Ángel llega a casa tuviese una discusión con Tatiana, recriminándola por el incidente previo del bar, no se ha practicado prueba detallada suficiente sobre el hecho de que los hematomas que presentaba en los brazos fuesen fruto de un intenso agarre, de una aprehensión violenta, consustancial a una disputa con violencia. Ahora bien: pero aunque diésemos por válida esta hipótesis, no se justifica de manera racional que después de este concreto enfrentamiento, cuando Jesús Ángel ya se había marchado a su habitación, se había sentado en la cama y por lo tanto podemos decir que había cesado la afrenta, Tatiana tuviese la necesidad de repeler ninguna agresión yendo a la cocina, cogiendo dos cuchillos, entrando en el dormitorio de Jesús Ángel y apuñalándolo». Y, respecto del miedo, deja claro también que «... tampoco resulta acreditado de la prueba practicada en el proceso la realidad de esta situación de temor, ni producida por lo que pudo ser la recriminación que se desarrolló en la vivienda a su llegada, ni tampoco basándose en el tiempo anterior durante el que se extendía la relación de convivencia con Jesús Ángel. Esta relación no refleja episodios, tensiones o actitudes que infundiesen sobre la acusada esa sensación anímica que atenazase su voluntad». 
intelectivas y volitivas, aunque sin llegar a anularlas. Desde la representación procesal de Tatiana se alega en un primer momento una eximente completa por intoxicación plena de «bebidas alcohólicas, drogas tóxicas, estupefacientes, sustancias psicotrópicas u otras que produzcan efectos análogos» (art. 20.2. ${ }^{\circ} \mathrm{CP}$ ) y, en su defecto, sucesivamente, una eximente incompleta (art. 21.1..$^{\mathrm{a}}$ e.r.c. art 20.2. ${ }^{\circ}$ ), una atenuante ordinaria muy cualificada o simple de grave adicción a tales sustancias (art. 21.2. ${ }^{\mathrm{a}}$ ) y, finalmente, una atenuante analógica (art. 21.7..$^{\mathrm{a}}{ }^{17}$, circunstancias personales o subjetivas cuyo fundamento reside en la exclusión o disminución de la imputabilidad de Tatiana.

En efecto, el consumo (consciente o inconsciente) de determinadas sustancias como las arriba descritas y su adicción a ellas pueden afectar con distinta intensidad a la comprensión del significado ilícito del hecho o a la capacidad de autocontrol del agente, por lo que suponen una forma específica de trastorno mental transitorio o alteración psíquica actual $^{18}$ (de ahí que no sea aceptable, como sin embargo intenta la representación procesal de Tatiana, alegar cumulativamente intoxicación y trastorno mental transitorio como si tuvieran diferente naturaleza) ${ }^{19}$. Para decantarnos por lo tanto por un tipo u otro de circunstancia modificativa de la responsabilidad criminal, tendrá que valorarse según los hechos probados el grado de intoxicación de Tatiana y sus efectos en sus capacidades de comprensión y decisión. A juzgar por lo señalado en los antecedentes de hecho, puede descartarse de entrada la eximente completa de intoxicación plena (así como en su caso habría de serlo la de trastorno mental), puesto que su aplicación solo sería posible si la ingesta hubiera alterado completa o casi completamente las facultades intelectivas y de autocontrol de Tatiana, lo que no fue el caso. Tampoco parece que estas se vieran afectadas de manera muy relevante o intensa (llegando a una situación de semiimputabilidad), lo que conduce a excluir la eximente incompleta del art. 21.1. ${ }^{\mathrm{a}}$ e.r.c. el art. 20.2. ${ }^{\mathrm{a}} \mathrm{CP}$ y nos mueve en cambio al ámbito de las atenuantes ordinarias, aunque con algunas dificultades.

En particular, para aplicar la atenuante del art. 21.2. ${ }^{a}$ es necesario que la disminución de las capacidades psíquicas del sujeto vaya acompañada de una adicción a las sustancias anteriormente descritas considerada como grave. Además, suele exigirse una conexión temporal y causal entre la alteración psíquica y el delito cometido: (i) así, el sujeto adicto tiene que tener sus capacidades mermadas en el momento de cometer el

17 Vid. especialmente las alegaciones reflejadas en la SAP de Madrid núm. 519/2015, de 17 de julio.

18 Para profundizar sobre estas cuestiones, véase Luzón PeÑa, Lecciones, PG, 3. a ed., 2016, 27/1-47.

19 En este sentido se pronuncia también la Audiencia Provincial de Madrid en su sentencia $\left(\mathrm{FJ} 8 .^{\circ}\right)$. 
delito, si bien alguna jurisprudencia exige prueba efectiva de ello y otra lo infiere de la mera ingesta de las sustancias; y (ii) además, la grave adicción debe haber conducido al sujeto a cometer el delito (que actúa «a causa de» su adicción), lo que ha sido interpretado de manera restrictiva por un sector jurisprudencial como la exigencia de que el delito tenga por objeto lograr dinero o medios para satisfacer las necesidades de consumo a corto plazo de las sustancias a las que el sujeto es adicto y proseguir así con sus hábitos ${ }^{20}$.

Lo cierto es que las sentencias comentadas admiten la aplicación de esta atenuante ordinaria en el caso de análisis al considerar probada pericialmente la grave adicción de Tatiana al alcohol y la merma de sus facultades psíquicas en el momento del hecho, sin exigir en cambio una conexión estricta entre el delito y la obtención o financiación de las sustancias objeto de la adicción (que, como se ha mencionado, sólo defiende un sector jurisprudencial). Sin embargo, aunque esta posición se considera apropiada, cabe advertir que podría no haber prosperado, siendo conveniente la búsqueda de atenuantes alternativas. En cuanto a los efectos concretos de la atenuante de grave adicción, si ya se ha descartado la eximente incompleta por no ser la alteración de las capacidades del autor muy relevante o intensa, lo más habitual es decantarse por la atenuante simple en lugar de por la muy cualificada, cuya frontera con la eximente incompleta es ciertamente muy borrosa, teniendo en cuenta la referencia a la gravedad de la adicción que ya se hace en el enunciado del art. 21.2. ${ }^{\mathrm{a}} \mathrm{CP}$.

Como segunda alternativa ante supuestos con alteración no muy intensa de las facultades intelectivas y volitivas por el consumo de determinadas sustancias, se destaca por parte de la doctrina la posibilidad de apreciar en estos casos una atenuante ordinaria de arrebato, obcecación o estado pasional de entidad semejante. Su naturaleza es también subjetiva o personal y su fundamento reside (al igual que las ya analizadas) en la disminución de la imputabilidad del sujeto, sin llegar a excluirla ni a reducirla de manera tan intensa como la correspondiente a una eximente completa o incompleta por trastorno mental transitorio. Ahora bien, lo cierto es que la jurisprudencia no suele recurrir a esta atenuante para amparar casos relacionados con la intoxicación por consumo de bebidas alcohólicas o drogas, prefiriendo en cambio (de no darse los requisitos de la atenuante del art. 21.2. ${ }^{\mathrm{a}} \mathrm{CP}$ ) el recurso a la atenuante analógica, motivo por el que no se desarrollará más esta alternativa y se pasará directamente a la siguiente.

Como se ha señalado con anterioridad, el artículo 21.7. ${ }^{\mathrm{a}} \mathrm{CP}$ admite expresamente una atenuante analógica si concurren circunstancias «de

20 Con más detalle, cfr. VÁzouez-Portomeñe SEIJAS, «La atenuante de grave adicción: un análisis jurisprudencial», Diario La Ley, n. ${ }^{\circ} 8699$, 10-2-2016. Recurso electrónico disponible en http://diariolaley.laley.es. 
análoga significación que las anteriores», lo cual no sería, a juicio de algunos autores, más que una manifestación específica de la posibilidad general de admitir la analogía in bonam partem. Sobre esta cuestión, cabe precisar que en algunos casos se interpreta la atenuante de forma algo restrictiva, exigiendo la semejanza con concretos elementos de una de las anteriores circunstancias atenuantes, mientras que en otros basta con que la circunstancia comparta los fundamentos de las circunstancias ya reconocidas, en el sentido de que disminuya el grado de injusto objetivo o subjetivo, de culpabilidad o, por otros motivos, el merecimiento o la necesidad de pena de los hechos.

En la práctica relacionada con el consumo de drogas o alcohol, suele prosperar el recurso a la atenuante analógica cuando falla alguno de los requisitos de la grave adicción pero sí concurre adicción o hay un estado de embriaguez que afecta a la comprensión del significado ilícito del hecho o a la capacidad de autocontrol del agente, sin llegar a tener una intensidad que lo haga merecedor de una eximente incompleta. Por eso, en el caso objeto de análisis parece razonable sostener la aplicabilidad de la atenuante analógica (con efectos simples) en caso de no hacerlo la de grave adicción.

b) La confesión posterior a la llegada de los policías locales

Por otro lado, se nos dice que Tatiana refirió espontáneamente a los agentes de policía que había apuñalado a su pareja con un cuchillo con la intención de matarla, lo cual nos permite valorar la posibilidad o no de apreciar una atenuante genérica de confesión (art. 21.4. ${ }^{\mathrm{a}} \mathrm{CP}$ ).

Se considera que la confesión por el sujeto activo constituye una forma de comportamiento postdelictivo positivo (pues el delito ya está consumado) que afecta a la punibilidad personal del hecho por razones de política criminal, en la medida en que supone una colaboración activa con las autoridades que facilita la investigación del delito y el descubrimiento de los responsables penales. Por lo general opera como circunstancia atenuante genérica, aunque en algunos delitos puede también suponer una causa personal de supresión o anulación de la punibilidad o un elemento típico atenuatorio ${ }^{21}$.

En cuanto a sus requisitos, cabe destacar que hoy en día no se exige que quien confiese lo haga por motivo de arrepentimiento por el hecho, circunstancia que no se daría por ejemplo en este caso. Basta a tales efectos con que un sujeto culpable aporte a las autoridades información veraz en lo sustancial de los hechos - es decir, sincera, ajustada a la realidad-, cualesquiera que sean sus motivos para ello. Ahora bien, el art. 21.4. ${ }^{a}$ sí

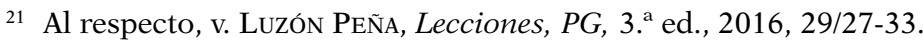


especifica un límite temporal para esta atenuante ordinaria: en particular, que la confesión del sujeto haya tenido lugar «... antes de conocer que el procedimiento judicial se dirige contra él». Para el Tribunal Supremo en diversas sentencias, ello exige que la confesión se realice antes del inicio de las diligencias policiales ${ }^{22}$, si bien alguna doctrina considera más correcto y respetuoso con el principio de legalidad ampliar el plazo hasta el procedimiento judicial en sentido estricto.

De este modo, si se interpreta este requisito incluyendo en él las diligencias policiales, debería concluirse que no concurre como tal en los hechos descritos, pues Tatiana sólo confesó durante la intervención de los agentes de policía para atender la llamada realizada por la propia víctima. Ello impediría la apreciación de la atenuante ordinaria, tanto en su versión simple como en su versión muy cualificada. Sea como fuere, la aportación de información veraz en lo sustancial, pero un poco posterior al límite temporal marcado por la interpretación jurisprudencial del art. 21.4. ${ }^{\mathrm{a}}$, comparte claras semejanzas con la atenuante de confesión y sus fundamentos generales, por lo que podría encajar sin problemas en los términos de la atenuante analógica, aunque sin llegar a merecer efectos muy cualificados. Así puede considerarse en este caso (como de hecho lo considera la Audiencia Provincial de Madrid), teniendo en cuenta el carácter espontáneo de la confesión, a pesar de haberse producido extemporáneamente para los estándares del Tribunal Supremo y no haberse acreditado la referencia a los malos tratos en relación con Jesús Ángel.

\section{c) La circunstancia mixta de parentesco}

Por último, se hace referencia en los hechos probados a la existencia de una relación de pareja entre la autora y su víctima, aunque la representación procesal de Tatiana pretendió cuestionar tal conclusión o, por lo menos, su estabilidad o equiparabilidad con una relación matrimonial. Resulta por lo tanto necesario valorar si cabría aplicar, y (en su caso) de qué modo, la llamada circunstancia mixta de parentesco.

Se trata esta de una circunstancia genérica recogida en el art. 23 CP y que puede operar como atenuante o agravante (y que por ello se diferencia de aquellos casos en que el parentesco constituye un elemento típico agravatorio o privilegiante). Según el texto del artículo, esta circunstancia se aplica al «cónyuge o persona que esté o haya estado ligada de forma estable por análoga relación de afectividad, o ser ascendiente, descendiente o hermano por naturaleza o adopción del ofensor o de su cónyuge o conviviente». Su fundamento es discutido, aunque para buena parte de la doctrina reside en el aumento del grado objetivo y subjetivo de injusto al aprovechar la confianza propia de las relaciones sentimen-

22 Así, por ejemplo, la STS núm. 43/2000, de 25 de enero (FJ 3. ․). 
tales o de parentesco e infringir los deberes más intensos de respeto para con sus integrantes ${ }^{23}$; en cambio, cuando la circunstancia opera como atenuante, su fundamento reside más bien en consideraciones de punibilidad por menor necesidad de pena.

La decisión sobre los efectos agravatorios o atenuatorios de esta circunstancia depende de «la naturaleza, los motivos y los efectos del delito», por lo que se trata de una cuestión de interpretación teleológica, axiológica y sistemática. La jurisprudencia tiende a considerarla agravante cuando afecta a delitos que protegen bienes jurídicos de naturaleza personal (vida, salud e integridad física, libertad) y como atenuante cuando lo hace con delitos contra el patrimonio (hurto, apropiación indebida, etc.). Sin embargo, pueden admitirse importantes excepciones, como por ejemplo en determinados casos de homicidios piadosos.

Entre los requisitos se incluyen la efectiva concurrencia de la relación de parentesco (con los límites señalados, que excluyen por ejemplo el parentesco en línea colateral salvo en el caso de los hermanos) o de la relación presente o incluso pasada de afectividad, siempre que esta última haya sido estable. A tales efectos, la jurisprudencia ha aclarado que no es necesaria la existencia de afecto o cariño entre autor y víctima, pues cuando se produce la agresión ya no suelen concurrir (por lo menos, no recíprocamente) tales emociones, salvo en algunos casos ligados al suicido o la eutanasia ${ }^{24}$.

En el caso que nos ocupa, teniendo en cuenta que ambos implicados formaban una pareja sentimental, no conyugal pero con relación de convivencia desde hacía más un año, no cabe duda —en línea con lo afirmado en las sentencias comentadas- de que los requisitos de la estabilidad en la relación se cumplen, por mucho que los afectos concretos se hubieran resentido o incluso hubieran desaparecido. En consecuencia, y teniendo en cuenta que se trata de un intento de asesinato y que no concurre motivo piadoso alguno (sino todo lo contrario), parece claro que habría de tener efectos agravatorios.

${ }^{23}$ Como señala el Tribunal Supremo en la sentencia comentada (FJ 9. ${ }^{\circ}$ ): «... la circunstancia de que se trata, en los casos en que debe operar como agravante, lo hace con la finalidad de dar respuesta a un injusto que es de carácter plural en sus dimensiones: la de la propia acción criminal ejecutada en ese contexto; la constituida por la infracción del deber de respeto del más próximo, socialmente valorado como de mayor intensidad del debido en general a cualquier persona; y, en fin, la representada por el aprovechamiento de la desprevención con que generalmente se mueve quien se sabe en un ámbito de relaciones presidido por la confianza, como es aquel en el que se convive (SSTS 26/2002, de 22 de enero, 926/2008, de 30 de diciembre y 1387/2009, de 30 de diciembre, entre muchas)».

${ }^{24}$ V., por ejemplo, la STS núm. 971/2013, de 11 de diciembre. De hecho, tras la reforma operada por la LO 11/2003, de 29 de septiembre, el enunciado del art. 23 CP permite expresamente su aplicación a situaciones en las que la relación de afectividad ya no está vigente (de ahí la referencia a que la persona «esté o haya estado ligada de forma estable por análoga relación de afectividad...». La cursiva es mía. 
A la vista de las anteriores consideraciones, el análisis de los hechos probados lleva a coincidir en lo esencial con la calificación jurídica realizada por la Audiencia Provincial de Madrid y posteriormente confirmada el Tribunal Supremo: estamos ante una tentativa acabada de asesinato en la que concurren dos circunstancias atenuantes simples (la de grave adicción del art. 21.2. ${ }^{\mathrm{a}} \mathrm{CP}$ o analógica en relación con esta, de una parte,

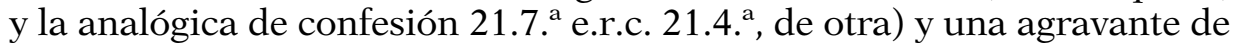
parentesco (art. $23 \mathrm{CP}$ ). Salvo los referidos problemas que se derivan del principio acusatorio, podría entenderse también, con alguna doctrina, que todo lo anterior se encontraría en concurso ideal con unas lesiones agravadas consumadas del art. $148 \mathrm{CP}$, en las que (conceptualmente) concurrirían las mismas circunstancias modificativas de la responsabilidad criminal. 


\section{RECENSIONES DE LIBROS}


